Naohiko Seki • Atsushi Hattori · Sumio Sugano

Yutaka Suzuki • Akira Nakagawara

Masa-aki Muramatsu • Tada-aki Hori • Toshiyuki Saito

\title{
A novel human gene whose product shares significant homology with the bovine brain-specific protein p25 on chromosome 5p15.3
}

Received: August 27, 1998 / Accepted October 21, 1998

\begin{abstract}
Here, we report on the sequence features and chromosomal location of a novel human gene which shares significant homology with the bovine brain-specific protein p25. Based on polymerase chain reaction analysis with a human/rodent monochromosomal hybrid cell panel and a radiation hybrid panel, the gene was mapped on to p15.3 region of chromosome 5 .
\end{abstract}

Key words Bovine brain-specific protein - Chromosome mapping $\cdot$ Radiation hybrid panel $\cdot 5 \mathrm{p} 15.3$

A brain-specific protein, p25, was originally isolated as a major protein in the partially purified fraction of bovine $\tau$ protein kinases (Takahashi et al. 1991), and its complete sequence was determined with a cDNA from a bovine brain cDNA library (Shiratsuchi et al. 1995). From immunohistochemical studies, p25 was localized in oligodendrocytes and neuropils (Takahashi et al. 1993).

A novel cDNA clone was isolated from a full-length enriched cDNA library constructed from a human neuroblastoma sample using the oligo-capping method described previously (Maruyama and Sugano 1994; Suzuki et al. 1997). A one-pass sequencing and database search revealed that this cDNA clone did not match any human genes. The entire sequence of the clone was determined by a shotgun strategy (Ohara et al. 1997). The isolated cDNA clone was $5019 \mathrm{bp}$ in length, and had an open reading frame of 219

N. Seki · A. Hattori · T. Hori · T. Saito $(\bowtie)$

Genome Research Group, National Institute Radiological Sciences,

Anagawa, Inage-ku, Chiba 263-8555, Japan

Tel. +81-43-206-3135; Fax +81-43-251-9818

e-mail: t_saito@nirs.go.jp

S. Sugano · Y. Suzuki

Department of Virology, Institute of Medical Science, The University of Tokyo, Tokyo, Japan

A. Nakagawara

Division of Biochemistry, Chiba Cancer Center Research Institute, Chiba, Japan

M. Muramatsu

Helix Research Institute, Chiba, Japan, and Department of Bioregulation, Medical Research Institute, Tokyo Medical Dental

University, Tokyo, Japan amino acids. The predicted protein had a calculated molecular weight of approximately $24 \mathrm{kDa}$. A homology search of the conceptual translated amino acid sequence revealed that it is most homologous to bovine brain-specific protein p25, having $90 \%$ identity at the amino acid level. The alignment of the amino acid sequence deduced from the human and bovine p 25 proteins is shown in Fig. 1. The nucleotide sequence data reported here will appear in the DDBJ, EMBL, and GenBank nucleotide sequence databases with the accession number AB017016.

We examined the distribution of the human p25 transcript in various tissues by reverse transcription-coupled polymerase chain reaction (RT-PCR). Primers corresponding to the separate exons of the messenger were used to differentiate the contaminating genomic DNA-derived PCR products. A clear common signal of the expected size was detected in all the tissues examined (data not shown). In contrast with Takahashi et al. (1991), who reported that bovine p25 was brain-specific, the obtained expression profile indicates that the human p25 gene is constantly transcribed in various tissues. It remains to be investigated if there is another human p25 homolog with a similar expression profile to bovine p25. Considering its ubiquitous expression in a wide variety of tissues, the gene described here seems to be involved in the basic housekeeping functions of cells.

Chromosomal assignment of the human p25 gene was done by PCR analysis of a human/rodent somatic cell hybrid panel and a radiation hybrid panel, as described previously (Seki et al. 1997; Saito et al. 1998). The specific amplified PCR primers were designed in the $3^{\prime}$-untranslated region of the gene (5'-GTTCGCCCGTCCTCACTAGCT-3'， 5'-GGATGGGCCAGGAGAGGTTAG-3', PCR product size 116bp). First, a specific amplified product for humans was detected only from the hybrid containing human chromosome 5 (data not shown). Then, we performed further mapping analysis using a PCRbased radiation hybrid panel (Genebridge 4, Research Genetics, Huntsville, AL, USA) with the same primers used in the assay for the human/rodent somatic cell hybrid panel. Statistical analysis of the radiation hybrid data was per- 
Fig. 1 Alignment of the bovine p25 gene (bovp25, accession number X85738) and the human p25 gene (hump25, accession number AB017016). Identities are indicated by a black background, and similar residues are shadowed. An asterisk denotes the termination codon

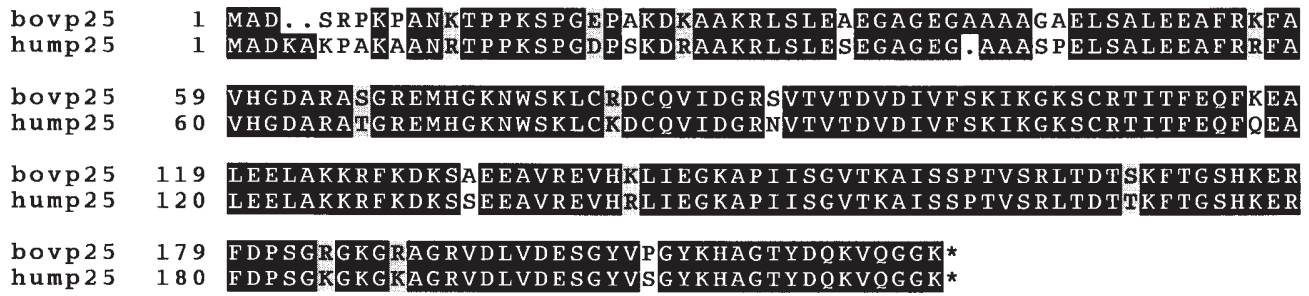

bovp 25

hump 25

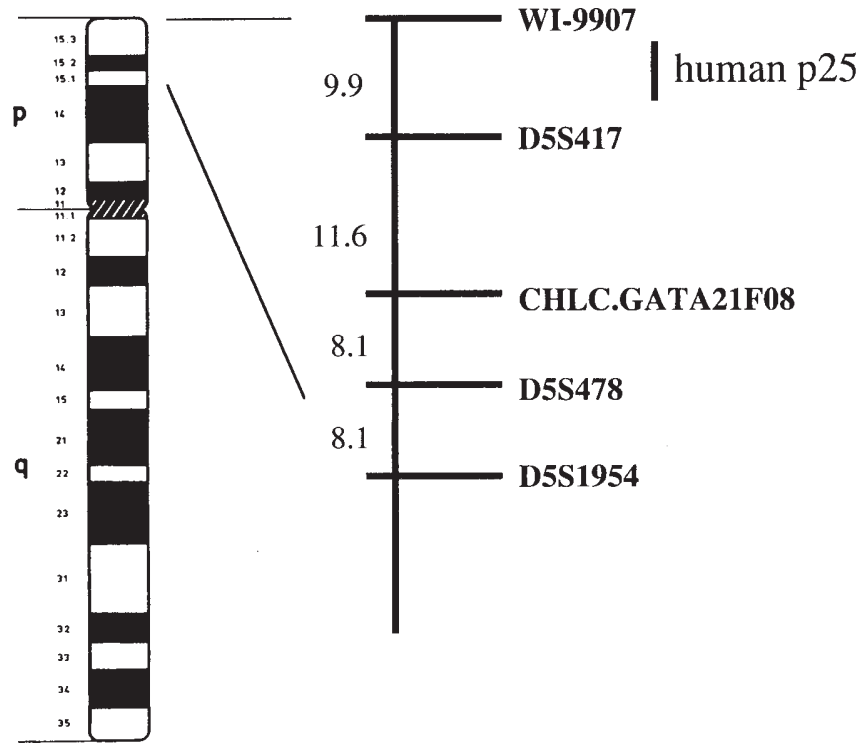

Fig. 2 Chromosomal placement of the human p25 gene at a relative distance to framework markers on the WICGR radiation hybrid map of the human genome. The approximate corresponding cytogenetic location of the gene on the telomeric region of chromosome 5 is indicated. Distances are in centirays

formed using the RHMAPPER software package (http:// www-genome.wi.mit.edu/cgi-bin/contig/rhmapper.pl). The data vector for the p25 gene was 00100001010011000000 00101001111100110000111001000000110001100110000010 01010000000010011001000 , and the resulting report indi- cated that the gene was mapped between markers WI-9907 and D5S417, both of which have been cytogenetically mapped to 5 p15.3 (Fig. 2). The position of the gene is 4.29 cR proximal to WI-9907.

\section{References}

Maruyama K, Sugano S (1994) Oligo-capping: a simple method to replace the cap structure of eukaryotic mRNAs with oligoribonucleotides. Gene 138: 171-174

Ohara O, Nagase T, Ishikawa K, Nakajima D, Ohira M, Seki N, Nomura N (1997) Construction and characterization of human brain cDNA libraries suitable for analysis of cDNA clones encoding relatively large proteins. DNA Res 4: 53-59

Saito T, Seki N, Yamauchi M, Tsuji S, Hayashi A, Kozuma S, Hori T (1998) Structure, chromosomal location, and expression profile of EXTR1 and EXTR2, new members of the multiple exostoses gene family. Biochem Biophys Res Commun 243: 61-66

Seki N, Nimura Y, Ohira M, Saito T, Ichimiya S, Nomura N, Nakagawara A (1997) Identification and chromosome assignment of a human gene encoding a novel phosphatidylinositol-3 kinase. DNA Res 4: 355-358

Shiratsuchi A, Sato S, Oomori A, Ishiguro K, Uchida T, Imahori K (1995) cDNA cloning of a novel brain-specific protein p25. Biochim Biophys Acta 1251: 66-68

Suzuki Y, Yoshitomo-Nakagawa K, Maruyama K, Suyama A, Sugano S (1997) Construction and characterization of a full length-enriched and a $5^{\prime}$-end-enriched cDNA library. Gene 200: 149-156

Takahashi M, Tomizawa K, Ishiguro K, Sato K, Omori A, Sato S, Shiratsuchi A, Uchida T, Imahori K (1991) A novel brain-specific $25 \mathrm{kDa}$ protein $(\mathrm{p} 25)$ is phosphorylated by a Ser/Thr-Pro kinase (TPK II) from tau protein kinase fractions. FEBS Lett 289: 37-43

Takahashi M, Tomizawa K, Fujita SC, Sato K, Uchida T, Imahori K (1993) A brain-specific protein p25 is localized and associated with oligodendrocytes, neuropil, and fiber-like structures of the CA3 hippocampal region in the rat brain. J Neurochem 60: 228-235 